\title{
Arica en las rutas de tráfico de Potosí: Algunas consideraciones sobre la sociedad andina del siglo XVIII*
}

\author{
Mario A. Rivera**
}

\section{INTRODUCCIÓN}

Los caminos que hoy llevan de los puertos del Pacífico al Altiplano Boliviano cumplen funciones muy similares a las vías terrestres que funcionaban en los siglos de la colonia, cuando Arica, también conocido como el puerto de La Plata, servía de entrada al azogue que provenía del Perú y salida de La Plata que era producida en Potosí.

Hoy día, las distancias modernas, 20 minutos en avión de La Paz a Arica, 8 horas en automotor, a una distancia de 400 kilómetros, corresponden groseramente a los 20 o más días que una recua demoraba en unir ambos puntos en los siglos XVII o XVIII. Por ese entonces, este trayecto se realizaba con los mismos propósitos que hoy, es decir, circulación de bienes. La noción de estas rutas tienen su origen en la época prehispánica, cuando caravanas de llameros recorrían el espacio andino, poniendo en contacto diversos entornos ecológicos y etnias. Tanto el conocimiento del camino como la administración del mismo y su mantención, así como las características de la dinámica de las caravanas y los bienes que circulaban, cumplían un rol muy específico en la organización social y política andina. La base ideológica que constituye parte fundamental de esta organización nos permite aventurar la hipótesis que estas rutas a larga distancia englobaban todo el mundo perteneciente al entorno circumlacustre de Titicaca, aun en tiempos preTiwanaku. Anteriormente ( $\mathrm{Ri}-$ vera, 1985), hemos señalado la importancia del agua en la ideología andina, y

\footnotetext{
* Una versión prelimiar fue preparada para Simposium: El Siglo XVIII en los Andes, organizado por el Centro Bartolomé de Las Casas y realizado en Chantilly. Francia, abril de 1993.

**Field Museum of Natural History. Chicago, USA.
} 
como la red de conductos acuateros interconectados da base al mito de Tarapacá o Tunupa, vinculando las tierras áridas del desierto de Atacama al centro mitológico titicaca. Recientemente hemos recuperado nuevas evidencias de sitios correspondientes al desarrollo Alto Ramírez en pleno desierto, en donde el rol del agua en la iconografía de personajes que navegan en balsas. y asociación de canales de distribución interna y otras obras acuíferas en establecimientos aldeanos tempranos confirma la vigencia mitológica de Tunupa y la participación incluyente del territorio costero al Titicaca.

Como se verá más adelante, la función de las rutas dependía directamente del desarrollo sociopolítico vigente. Por ejemplo, durante la vigencia de Tiwanaku y los Desartollos Regionales en los períodos medios e intermedio tardío ( 400 a 1.300 d. C.), las rutas mantenían una vinculación efectiva entre las distintas etnias, reconociéndose como entidades de envergadura mayor producto del trabajo colaborativo en las que diferentes etnias cooperaban. Es decir, las rutas constituían obras de servicio mutuo y por tanto de carácter neutro, que facilitaban la comunicación. Con la expansión incaica, las rutas continúan ejerciendo un servicio de utilidad pero se les implanta una administración diferente, centralizada y jerarquizada. Con la dominación hispánica, la Corona introduce nociones mercantilista en cuanto a la forma y fondo de los bienes que circulan, lo que afecta la administración de las vías y la organización de los agentes comunicadores, especialmente recuas y llameros.

El presente trabajo constituye una visión preliminar de las rutas desde los puertos del Pacífico al Altiplano, durante el siglo XVIII. Representa parte de un proyecto mayor aun en desarrollo, por medio del cual nos proponemos estudiar las rutas prehispánicas de largo alcance con el objetivo de conocer el papel que han jugado en la transformación de la sociedad andina hasta el presente. Para ello estudiamos las rutas en época prehispánica para ver su desarrollo y evolución a través del tiempo, y, especialmente, su rol, en la conformación de la sociedad. En seguida, el rol del Incanato y, por contraste, las rutas con la dominación española, para concluir con el rol de las rutas en la sociedad andina presente. Partimos de la base que las rutas han servido de agente multifacético a la sociedad andina para su adaptación a las cambiantes realidades que comienza a vivir a partir del siglo xIv, y más dramáticamente durante el período colonial hispánico y en el presente siglo. De allí que nos interese conocer cómo han sido reutilizados sitios preincaicos, así como tambos incaicos distribuidos en una red de comunicaciones, y de esta forma, recuperar información útil que nos permita comprender la funcionalidad y valor de las propias instalaciones. Este propósito también tiene que ver con mi propio interés por la arqueología, la etnohistoria y la geografía, disciplinas éstas que de esta forma colaboran en el estudio de una hipótesis común.

De tal forma que presentamos aquí una primera aproximación de este problema, que consiste en cómo entender el valor de las rutas respecto de las organizaciones sociopolíticas en desarrollo de las comunidades andinas. 
Platt (1987:216), por ejemplo, ha argumentado anteriormente la validez de la hipótesis sobre la internación del mercado en las comunidades andinas como una estrategia indígena para subsistir, manteniendo el orden básico interno. Esta visión contrasta con la de una simple imposición colonial y tiene su réplica en la forma en que continúa utilizando la vía de Arica a través de uno de los últimos envíos de azogue en el siglo XVIII. Interesante de considerar aquí son las distancias, las recuas y su organización para llevar a efecto la actividad de arrieraje, además del sentido empresarial que adquiere. Para comprender cómo se efectuaba el traslado de tanto volumen de mercadería, nos referiremos a continuación al movimiento caravanero prehispánico y su relación con sitios arqueológicos incaicos, para, finalmente entregar algunas conclusiones sobre esta investigación inicial.

\section{Potosí, Guancavélica y ARica: circuito de la Plata y el Azogue}

"Tienen estas minas sus escalas o caminos desde la superficie a la profundidad, $i$ por alli suben los indios las piedras en hombros, del metal que otros compañeros han despegado a punta de barreta, en cotamas, que son costales de pellejos a modo de zurrones; $i$ en llegando arriba, ponen la carga que sacan de una vez en montones diferentes: a cada uno de éstos llaman mita, i al lugar donde los van asentando, cancha. De estas canchas se lleva el metal a los injenios, cargado en carneros de la tierra. Injenios son ciertas máquinas de madera cuyas ruedas, llevadas de golpe del agua, levantan unos mazos grandes, que por su orden vuelven a caer sobre el metal i le muelen hasta hacerle polvo; este polvo o harinas se van poniendo en hoyos cuadrados que llaman cajones, alli les echan azogue i otras mezclas convenientes para que de la lei, esto es despliegue la plata, $i$ aquella piedra o tierra con que nació incorporada; i para conseguirlo mas brevemente se ayudan del fuego $i$ calor que les encaminan por ciertos buitrones, aunque ya se tiene por mejor valerse del sol; i cuando por las pruebas conocen que tiene estado, lo echan en unas tinas como medias pipas, i alli lo van lavando dentro de la tina a fuerza de brazos, con un molinete que es a la traza de rodezno. Suélese escusar parte del trabajo valiéndose del agua para rodar el molinete, i cuando se hace asi to llaman lavadero. Lavado el metal, sacan la plata i azogue en una pella, pónenla en un anjeo (aspecto de lienzo tosco), tuercen, golpean hasta que despide el agua $i$ algo de azogue; luego lo meten en moldes i tornan a golpearla hasta que toma forma de piña; ésta ponen en un hornillo de barro que llaman desazogaderas, i a fuerza de fuego le van quitando de todo punto al azogue, cayendo atajo en un barreño de agua que llaman vilque: de alli sale la piña algo granujada, asientan la plata con un martillo, con que queda acabada esta obra hasta hacerla barras i ensayarla". 
Así describe el virrey Mendoza, Marqués de Montesclaros, el trabajo de la plata y el azogue en Potosí a comienzos del siglo XVII (Dagnino, V. 1909:82).

Potosí fue descubierto en 1545 y según don Lamberto Sierra, tesorero de Potosí a fines del siglo XvI, llegó a producir 1.647.901.016 pesos contablizados hasta el año 1800. Según documento 1795 (legajo 75 de Hacienda, Sala 9, C. 1A.8 N.6, Archivo Nación Argentina), la mita de Potosí produjo en las cinco provincias siguientes que la integraban tributos hacia 1780 de:

$\begin{array}{lc}\text { Porco } & \$ 34.689 " 7 \\ \text { Chayanta } & 50.445 " 4 \\ \text { Chichas y Tarija } & 17.983 " 63 / 4 \\ \text { Lipes } & 3.532 " \\ \text { Atacama } & 6.429\end{array}$

En 1564 se descubren las minas de azogue en Guacanvélica, sur del Perú.

El virrey Marqués de Montesclaros describe así el proceso de extracción:

"Sale de la mina, en tierra y piedra; quebrántala en pedazos menudos, i dentro de costales, sobre carneros de la tierra, lo hacen bajar sus dueños al asiento donde tienen fundicion $i$ hornos de diferentes maneras. Los comunes $i$ que mejor han probado, que llamar de jabecas, son largos i angostos, no mas altos que a la cintura, descubiertos por arriba en la haz; dentro del hueco van metidas unas ollas de barro llenas de metal, cubiertas con otras vasijas de lo mismo, que llaman caperuzas. Danles fuego por el lado, veinticuatro horas $i$ mas; sirveles de leña yerba como paja que llaman icho y que nace silvestre en las tierras frías. Cuando va por el tino conocen ha dado la lei, lo dejan enfriar. i destapando las ollas hallan algun azogue que llevó el humo al cielo de las caperuzas, i el resto sacan lavando poco a poco la tierras de cada olla, i lo echan en los vólques vidriados, con lo cual se perfecciona una cosa tan importante que sin ella mal pudiéramos gozar de la pista i del oro que por su medio nos viene a la mano i posesión". (Dagnino, 1909:86).

El transporte del azogue se hacía en llamos desde Guancavélica hasta Chincha, desde aquí en barco hasta Arica, y luego, nuevamente en llamos hasta Potosí. A su vez, desde Potosi se acarreaba la plata que debía ser embarcada en Arica con destino a las Cajas Reales en España. A pesar que las llamas fueron reemplazadas por mulas a fines del siglo XVI, su costo y dificultad para criarlas, hacía mas expedito el transporte en llamas, que siempre fue preferido.

A partir de 1657, según memorándum de Juan Bautista Sáenz Navarrete (documento 149, Charcas 29-9, Archivo General de Indias) el transporte del azogue a Potosí se hizo por Buenos Aires, considerando que Guancavélica ya no producía cantidades importantes y el azogue debía viajar distancias mayores desde Europa, lo que abarataba los costos de transporte. Otra razón para este cambio de rutas la ofrece el citado Vicente Cañete y Domínguez, aducien- 
do que Arica y Tarapacá no entran en la composición de la provincia de Potosí y que Arica además conforme parte de la Audiencia de Lima y del Virreinato del Perú, lo que hace más difícil el control de traslado de mercancías de valor. Con el virreinato de La Plata, creado en 1776, la audiencia de Charcas completa pasó a su dominio y por tanto Cañete y Domínguez argüía que el traslado de azogue podía ser mejor controlado.

Mientras, Arica como ciudad y puerto comienza a activarse a partir del último tercio del siglo Xvi. Pero es realmente durante el xvII y la primera mitad del siglo xviII donde se desarrolla como plaza comercial importante. Sin embargo, las pestes y lo malsano del clima. plagado de malaria hasta entrado el siglo XX, constituyen una dificultad insalvable para el desarrollo económico y social de esta región. Las reclamaciones interpuestas por los oficiales de la Real Caja al virrey en 1611 son un pálido reflejo del descontento por servir en estas comarcas. Brevemente citemos parte de esta reclamación interpuesta por Agustín de Torres y Juan Bautista de Ureta, el 23 de mayo del citado año, y consignada en Dagnino (1909:47-48).

"Aunque en algunas ocasiones cada uno de nosotros en particular hemos dicho a $V$. Excelencia cuánta es la miseria y cortedad de los salarios de nuestros oficios $i$ cuán trabajosamente pasamos con ellos, la demasiada necesidad nos obliga a significar a V. Excelencia que ochocientos pesos ensavados que cado uno tenemos al año no es suficiente para sustentarse en esta tierra el hombre mas humilde de ella: pues, como es notorio, este lugar es el mas caro, incómodo i del mas desabrido in enfermo temple de todo el reino...

...I a esta Caja viene a parar i se despacha de ella toda la plata de las de Potosi. Oruro, La Paz i demas partes de arriba, i aqui se reciben i benefician todos los azogues que por cuenta de Su Majestad vienen de los Reinos de Castilla i de Guancavélica, estando a nuestro cargo el trajin de ellos, que solo esto último es de mas trabajo i riesgo que puede haber en ninguna otra Caja, i en que Su Majestad es mui servido. Demas de que, aunque las rentas de este partido no son tan cuantiosas como las del Callao i Lima, tienen la misma ocupacion i son unos mismos jéneros i dan el mismo cuidado, i solo no hai cobranza de tributos de indios. Sin que parezca exajeracion, podemos certificar a V. Excelencia, que por solo vivir en Arica, cualquiera hombre honrado merece mucho premio, pues demas de las continuas enfermedades i riesgos de tal vida, tiene otras tan malas calidades que exceden a lo peor del Reino, $i$ en suma se vive entre marineros, venteros i arrieros; en consideracion de lo cual i de que siempre hemos acudido al servicio de Su Majestad i de V. Excelencia en todas las cosas i casos que se han ofrecido $i$ han estado a nuestro cargo con mucha puntualidad...".

Huelgan comentarios para justificar la presencia de Arica en el trajín del azogue y el embarque de La Plata, a no ser por su excelente posición geográ- 
fica. Cabe destacar, sin embargo, que tal acción de los oficiales reales se restringió en todo momento a sus funciones en Arica propiamente tal, sin incursionar en el territorio que iba más allá de los límites de la ciudad. El verdadero trajín desde y hacia Arica fue dejado en manos de señores andinos que, como veremos, organizaban estos traslados como verdaderas empresas.

\section{El Espacio y las Rutas}

En la administración de las rutas y la organización del sistema de traslado de bienes y mercaderías, especialmente plata y azogue, era muy importante tener clara conciencia de las distancias entre los puntos claves así como el tiempo que se demora en cubrirlos. Esto, más los riesgos y recursos que cada entorno en particular podía ofrecer, constituían experiencias propias de aquellos contados señores andinos que se atrevían a montar semejantes expediciones.

De Buenos Aires a Potosí se contabilizaba una distancia de 450 leguas (y en 150 leguas por lo menos no pasan carretas) y de Potosí a Arica hay 112 leguas. (Doc. 149-Charcas, AGI). Sumamente instructivo en este aspecto es la carta geográfica levantada por don Pedro Vicente Cañete y Domínguez, quien fuera Gobernador Interino de Potosí en 1787 (Cañete y Domínguez (1791) 1952, Larraín 1974). Siguiendo esta carta, figuran las siguientes distancias:

San Pedro Atacama a Potosí: 139 leguas siguiendo el derrotero:

San Pedro a Chiu Chiu: 18 leguas

Chiu Chiu a Santa Bárbara: 12 leguas

Santa Bárbara a Polapi: 8 leguas

Polapi a Tapaquilchas (Lípez): 19

Tapaquilchas a Visacachillas: 8 leguas

Viscachillas a Alota: 7 leguas

Alota a Río Grande: 15

Río Grande a Amachuma: 16

Amachuma a Agua de Castilla: 9

Agua de Castilla a Cordillera de los Frailes: 10

C. de los Frailes a Porco: 8

Porco a Potosí: 9 (Total: 139 leguas)

Este camino, señalado en el mapa de Cañete y Domínguez. (Charcas 694, Ref. 160, AGI) (véase mapa 1) desciende hasta el puerto de Cobija, en la costa del Pacífico (confrontar con mapa de Cobija, carta 156, Charcas 438 AGI, de fecha 16 de Dic.-1785, levantado por Josef Agustín de Arze, con ocasión de la visita de los Indios de los Partidos de Lípez y Atacama, y reconocimiento del puerto de Cobija por orden de don Juan del Pino Manrique en informe al Marqués de Sonora (Hidalgo 1983, Bittmann 1983) (véase mapa 2). 
En carta de Antonio Romero de Tejada dirigida al Sr. Director General de los Reales Rutas de Correos, fechada el 26 de mayo de 1798 (Correos 464 AGI) se señalan las distancias oficiales por ordenanza sobre incorporación a la renta de correos de las conducciones de azogues y caudales en los dominios del Perú y río de La Plata. Desde

Buenos Aires a Jujuy: 410 leguas

Jujuy a Potosí: 132 leguas

Potosí a Oruro: 62 leguas

Oruro a La Paz: 48 leguas.

En nota del Marqués de Loreto, virrey de La Plata al Gobernador Intendente de La Paz, fechada en Buenos Aires 21 de febrero de 1789 (Hacienda Legajo 53, ANA), se señalan las siguientes distancias:

Arica a Oruro: 110 leguas

Arica a La Paz: 95 leguas

Arica a Chucuito: 125 leguas

Arica a Carangas: 55 leguas

Arica a Sajama: 36 leguas

Arica a Guanta (en Lluta): 7 leguas.

Nuevamente, esta información se puede complementar con el mapa de Cañete (mapa 1). En éste se indica el camino de Potosí a Arica como una ruta directa que une Potosí con Porco, cordillera de los Frailes, Ullaga, Paria, Salinas de Garci Mendoza hasta entroncar con los altos de Arica. A su vez, Dagnino señala que este camino entroncaba en Caquena y Parinacota, en el altiplano ariqueño (Dagnino 1909:112). Para llegar a estos puntos, se puede subir a lo largo del valle de Lluta, o bien por Azapa sólo hasta Chilispaya y Livílcar. Tanto Azapa como Lluta ofrecen buenos pastos y clima benigno, hasta Jamiraya en Putre, a tres mil quinientos metros de altura por el valle de Lluta. De allí se asciende hasta la laguna de Chungará a los pies de Parinacota para cruzar en tierras de Carangas bifurcándose el camino uno hacia Oruro, otro hacia Potosí. Una tercera vía de mucha frecuencia, unía el valle de Tacana y la quebrada del Tacora hacia Oruno, Garci Mendoza y Potosí. Fue conocida como la vía de La Paz (Dagnino 1909:1 12-113).

\section{LA ORGANIZACIÓN DE UN TRASLADO DE AZOGUE DESDE ARICA EN EL SIGLO XVIII}

A continuación nos referiremos a uno de los últimos envíos de azogue que utilizó el puerto de Arica en su desplazamiento hacia Potosí, reviviendo las antiguas rutas caravaneras. Este azogue, que en este caso particular fue elaborado en Alemania, debía haber entrado originalmente por Montevideo, siguiendo las rutas que se utilizaron durante todo el siglo XVIII y parte del siglo anterior, desde la creación del virreinato de La Plata (véase mapas 3 y 4). 


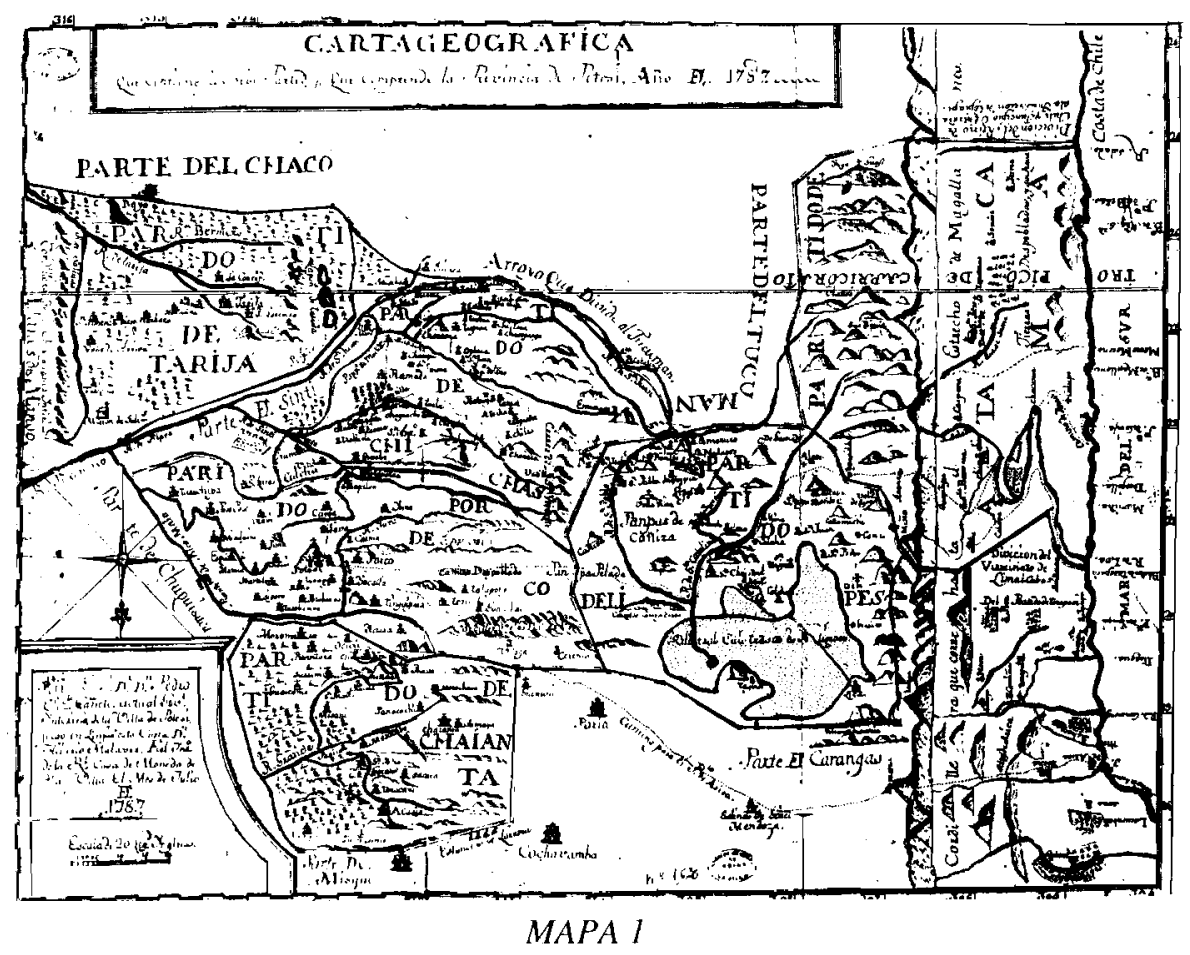

Carta Geográfica que contiene los partidos que comprende la provincia de Potosí, año 1787.

Los mapas señalados son muy instructivos pues muestran que hacia mediados del siglo xvin la ruta Buenos Aires-Salta-Potosí representaba todavía innumerables peligros debido a las continuas revueltas de "indios infieles" y la escasa población hispana asentada en la región y que dificultaba las comunicaciones.

Así, los mapas 4-A y B muestran el río de La Plata, Paraguay y afluentes. Fueron levantados por el gobernador de Tucumán D. Joaquín de Espinosa en 1759 y enviado al Gobernador de Potosí D. Ventura Saltelices. Indica muy bien el avance de las expediciones desde Salta a Asunción y de Corrientes a Salta. El siguiente mapa es complementario del primero, y puede observarse con más detalle los nombres de las poblaciones mencionadas en el anterior. El mapa 3, en cambio, corresponde a una relación geográfica de las provincias de las gobernaciones del río de La Plata, Tucumán y Paraguay, pero incluye también Chile, Bolivia y sur del Perú. Fue confeccionada en 1685 por el cosmógrafo mayor del virreinato de Lima, y compara muy bien ambas rutas, la oriental, a lo largo del río de La Plata hasta Salta y Potosí, y la ruta occidental, desde Arica a Potosí. La distancia es efectivamente mucho más corta $\mathrm{y}$, además, constituía Arica una ruta más segura donde había más experiencia en el traslado de bienes. 


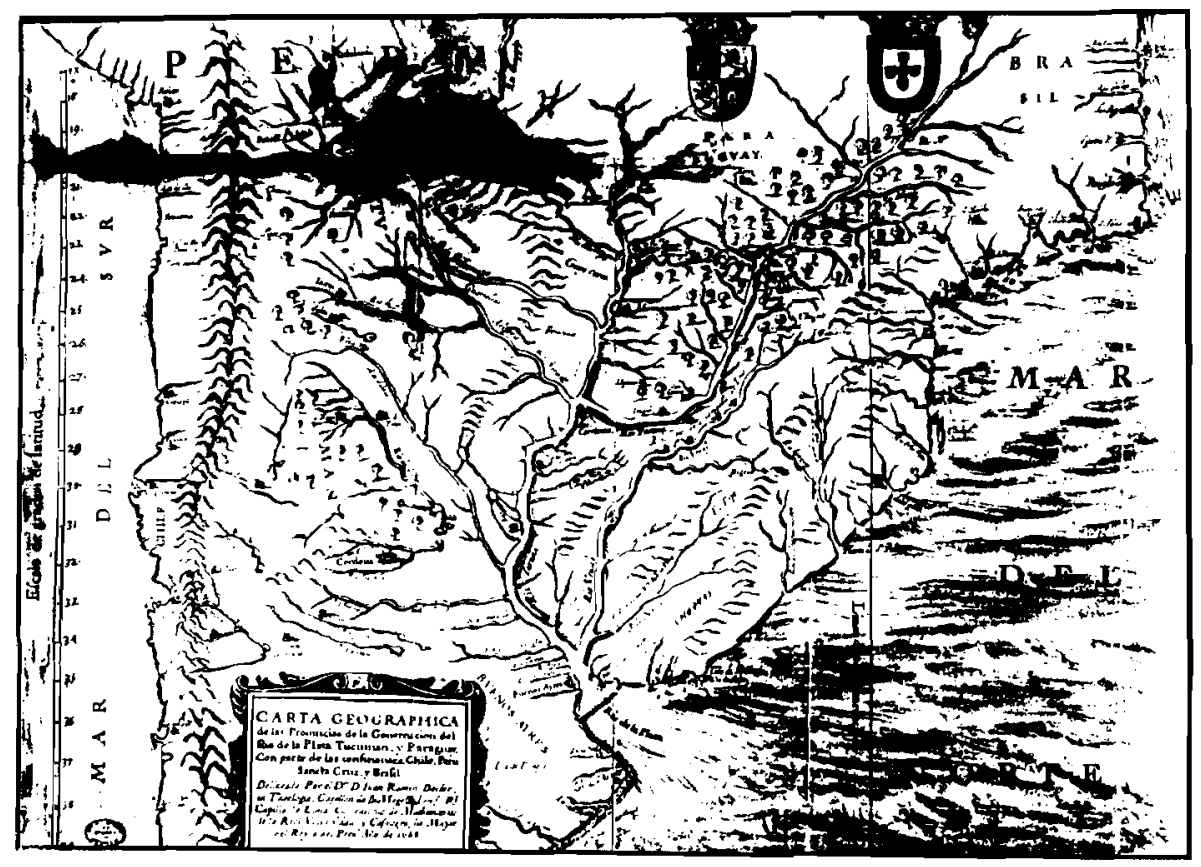

MAPA 2

Demarcición del puerto de Cobija.

En el Archivo de la Nación Argentina se encuentra un expediente completo relativo a las incidencias del otorgamiento del traslado del azogue desde Arica al altiplano, asunto que originalmente se le había propuesto a don Simón Núñez, natural de Sica Sica, en el traslado de 2.000 quintales de azogue proveniente de España (ANA-Hacienda Leg. 53). El año 1788, Juan de Dios Valles y Requesens, comerciante de Cádiz y dueño del barco Nuestra Señora del Rosario, propone entrar por Arica. Su solicitud es aprobada por el presidente de la Audiencia del Contrata y por el rey. El valor del flete fue tasado en 6 pesos por cada quintal, haciendo un total de \$ 12.000. El 29 de agosto del mismo año don Antonio Valdés comunica al Superintendente General y Subdelegado de Azogues y Minas en Buenos Aires sobre la decisión del viaje.

\begin{tabular}{lcccc} 
& Leguas & Flete/Mula & Quintales/carga & Flete/quintal \\
\hline Arica-Oruro & 110 & 14 a 15 & 3 & 5 \\
Arica-La Paz & 95 & 13 & 3 & $422 / 3$ \\
Arica-Chucuito & 125 & 18 & 3 & 6 \\
Arica-Carangas & 55 & 12 & 3 & 4 \\
\hline
\end{tabular}




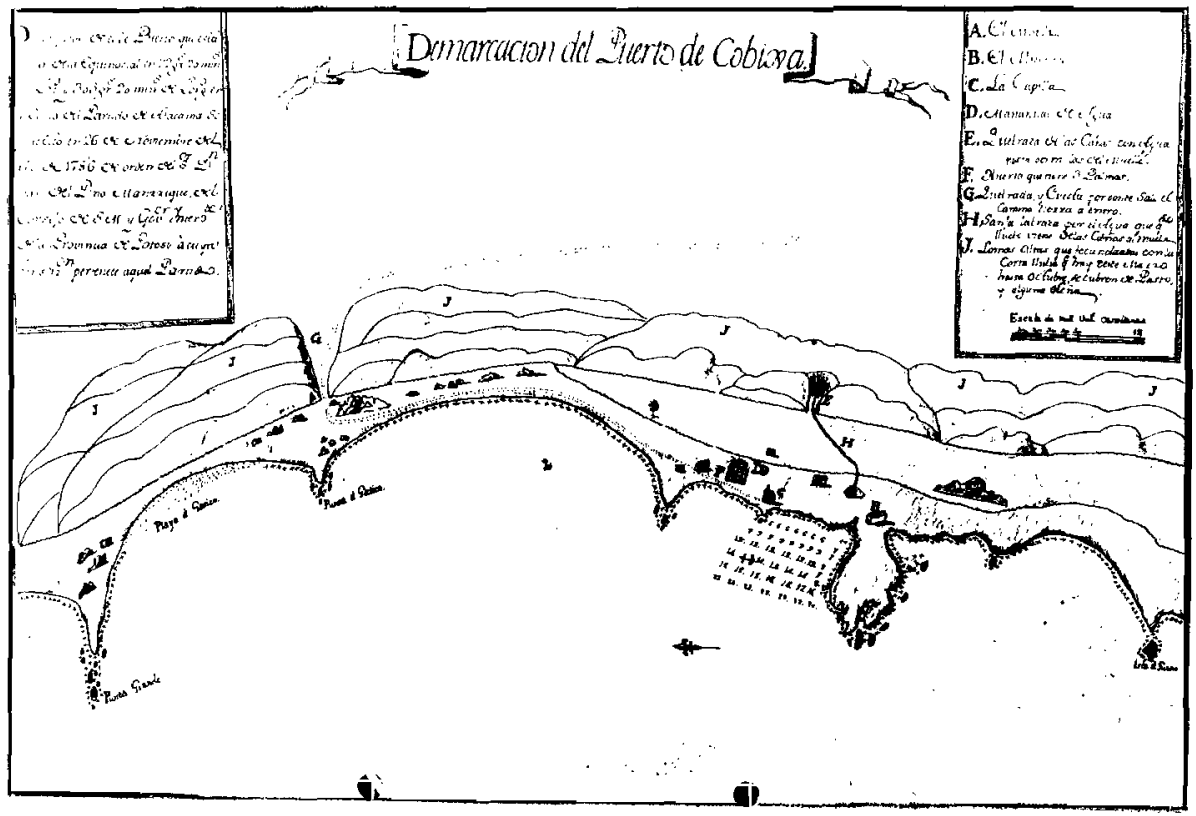

MAPA 3

Carta Geográfica de las provincias de la Gobernaciones del río de La Plata, Tucumán y Paraguay.

Adjunto a esta nota, el Marqués de Loreto envía una relación al gobernador intendente de La Paz en que se expresan los fletes por la distancia a servir: La carga de azogue, según instrucciones se componía de 1.333 cajones de 1 $1 / 2$ quintal y un quintal sobrante, haciendo el total de 2.000 quintales, para ser distribuida de la siguiente manera:

200 cajones a la Tesorería de Carangas

100 cajones a la Tesorería de La Paz

600 cajones a la Tesorería de Chucuito

433 cajones a la Tesorería de Oruro.

Se pagaría la siguiente refacción al asentista:

Desde Potosí a Oruro : $1 \%$

Desde Potosí a Carangas : 1 1/2\%

Desde Potosí a La Paz : $1 \%$

Desde Potosí a Chucuito: $2 \%$

Ante el pedido de la Real Hacienda transmitida a las instancias limeñas y paceñas por el virrey de La Plata Marqués de Loreto, el escribano de S.M. Crispín de Vera y Arao cita a La Junta de Gobierno de Real Hacienda en abril 


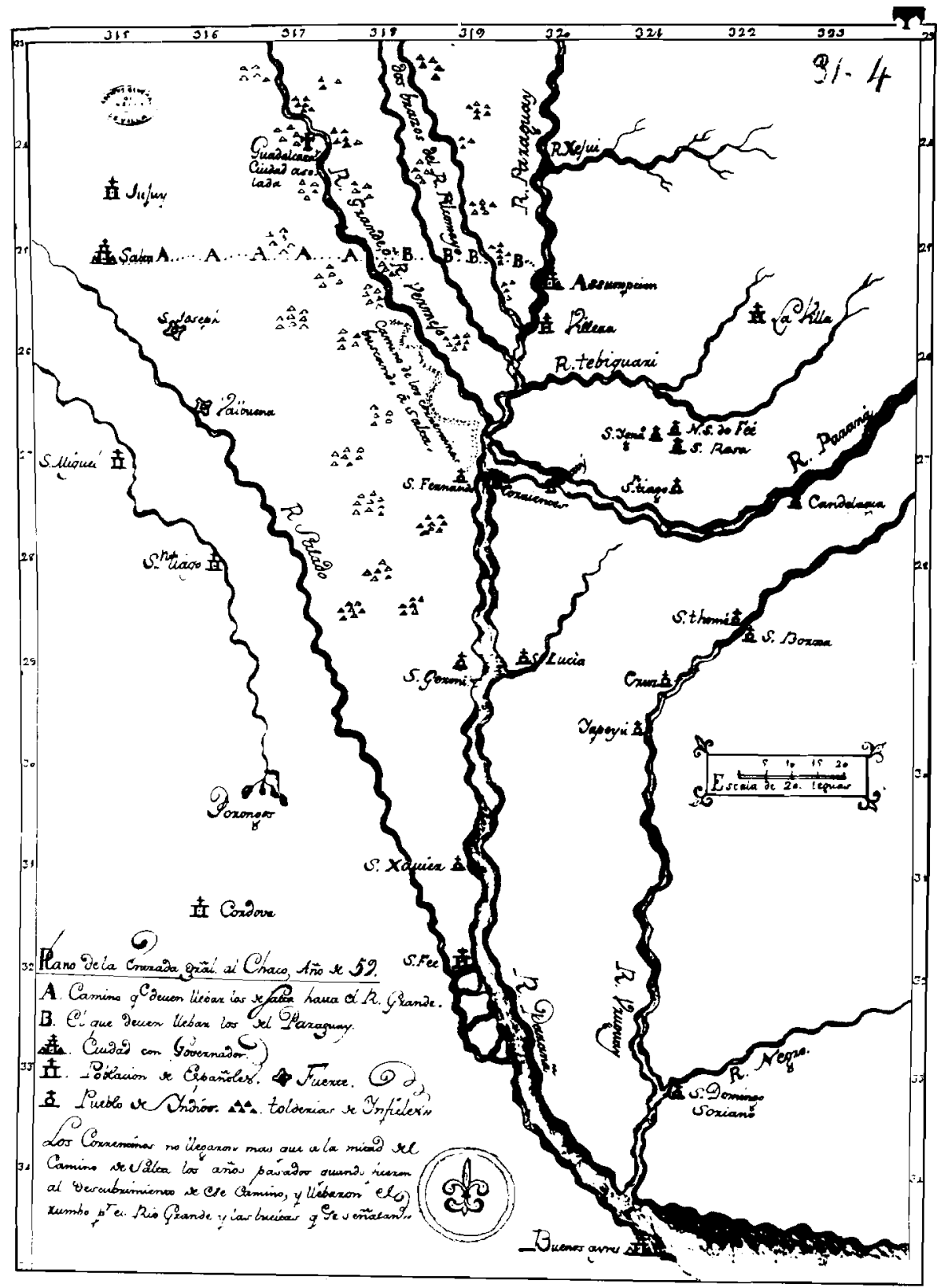

MAPA 4-A

Plano de la entrada general al Chaco 1759 


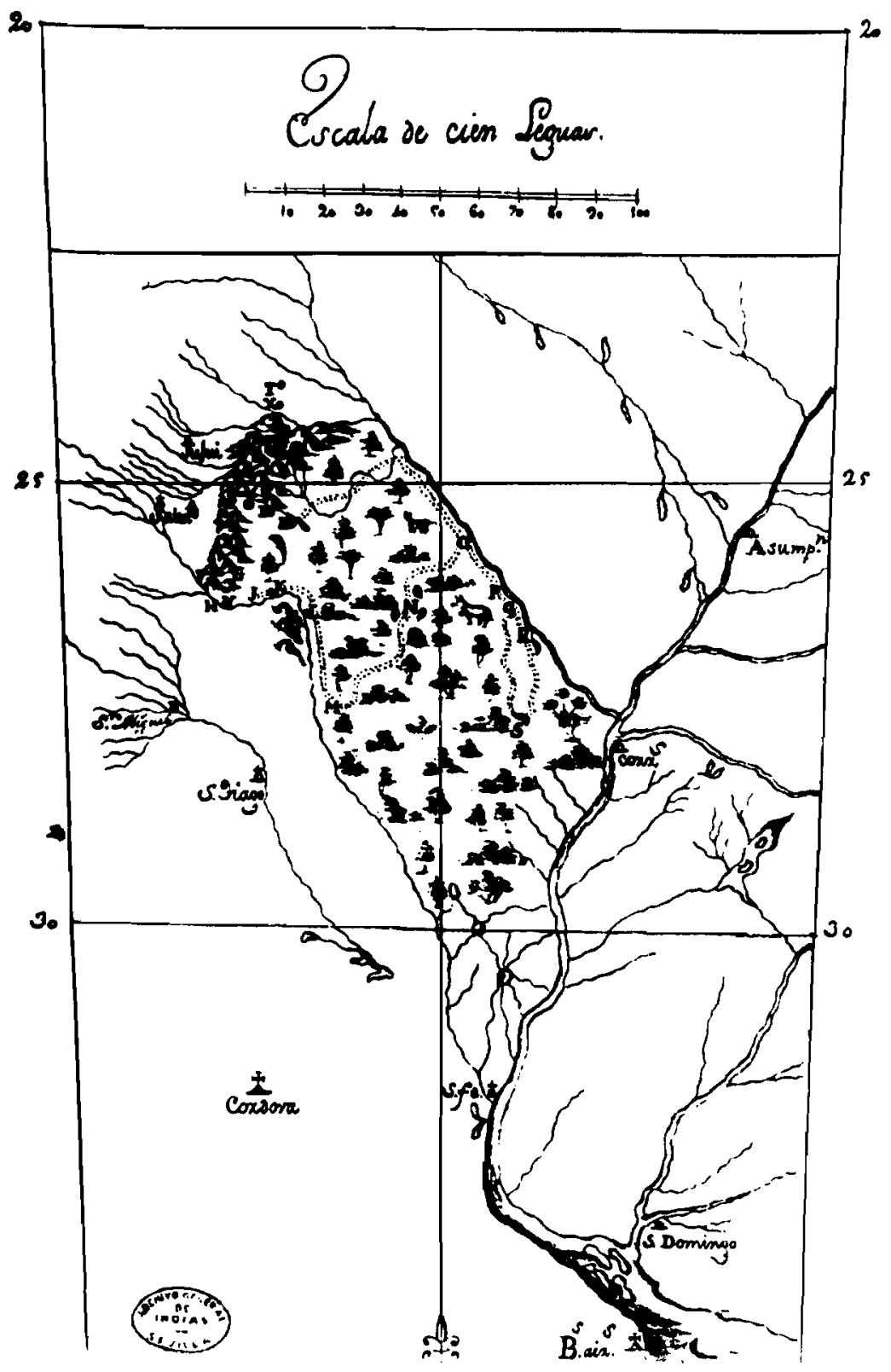

\section{MAPA 4-B}

Mapa geográfico del terreno que ocupan los fuertes de las fronteras de Salta, Jujuy, y lo demás descubierto en la jornada que hizo en 1759 el Gobernador de Tucumán D. Joaquín de Espinosa. 
de 1789 "para tratar el modo más cómodo y económico para dar cumplimiento a las disposiciones del virrey de La Plata acerca del recibo, repartición y conducción de los 2.000 quintales de azogue, distribución y caloración de los maitos, asegurar el crecido número de badanas para reforzar los maitos en su transporte" (Acta reunión Junta Gobierno de Real Hacienda, 20 abril 1789, Hacienda Legajo 53, expediente 1.360, ANA). La Junta decide además la contratación del minero de Sica Sica don Simón Núñez para la conducción de esta partida según se ha expresasdo anteriormente. Cuando éste sabe de la designación envía carta de contestación a la Junta donde fija sus condiciones.

"en cuanto a fletes, para satisfacer a los arrieros y para mayor seguridad en las respectivas distancias que han de caminar las 4000 badanas o maitos de azogue, ha de ser indispensable el reconocimiento de cada una de ellas al tiempo de recibirlas, y sacarlas de los barrilitos bien acomodadas, ya por estar flojas sus amarras, ya porque esta conforme el tiempo el mismo material quema o pudre las badanillas, o se ubieren varado contra la madera o algun clavo, puesto cabe toda precaucion, donde ocurren continuos vaivenes, y no pocas casualidades, y ya porque no es posible volverlas a acomodar en los mismos barrilitos que quedan inútiles e inservibles: se manda acomodar necesariamente, y según práctica, cada maito en una badana que resista, y precaucione los inconvenientes que se dejan ver. procurando el que cada una se vaya atando con los cordeles a propósito de acarreo, despues de mojados, a toda fuerza de dos hombres, e industria de ciento estaquillas que daban manejar.

Después de toda esta maniobra que depende de asistencia personal y conocimiento por menor, asi para el acomodo con la humedad y las condiciones de los cajones que han de caminar a saber: de 3 en maitos por tercio, ya se deja ver son necesarias 666 mulas con mas una que conduzca los dos maitos que sobran; 4000 badanas útiles, y reforzadas, que como va dicho han de servir para resguardar el giro de cada uno de aquellos maitos e demandelas que se graduen de refacción, no solo para que lleven los arrieros, sino que para reponer las que resulten quemadas, o podridas al tiempo del percibo y entrega que ha de proceder en Arica, de modo que si se comprasen hasta 4500 badanas, también son precisos otros tantos cordeles fornidos de acarreo, madera como son tablas de cedro, clavos, cueros de vaca, para las precintas de los 1333 cajones en que parecen se havan de acomodar los dichos maitos de azogue, y asi mismo unos dos a cuatro oficiales de carpinteria pues nada de lo dicho se encuentra en Arica, y se hace indispensable llevarlos desde esta ciudad, para lo que se han de emprender gastos de fletes de mulas, y otros que sean consiguientes.

Ultimamente sería conveniente que los arrieros conforme a sus destinos, vavan al reparo de un mozo, o caporal nacional que los gobierne, pues es 
constante las contravenciones que se acarrean por la decidia de aquellos, y aun por las irrupciones que cometen, cuando no tienen quienes les impidan y sujete.

Es cuanto puedo informar a US en el particular mediante la práctica que tengo experimentada por lo que he visto; y sucedió conmigo en ocasión que fue de orden de US a recibir en el mismo puerto los azogues que arribaron en el año pasado de 1786". Paz 14 Mayo 1789. Simón Núñez.

Doce días más tarde le escribía Francisco Javier de Santelizes, desde la Paz, ofreciéndose para hacer la conducción y reparto del azogue en las siguientes condiciones:

"1. es condición quese me ha de satisfacer; a razón de 8 pesos, por la conducción de cada quintal, dándoseme la mitad de su total.

ltem - que se ine han de dar, además de los $\$ 8$, la refacción que fuese de costumbre.

ltem - que seria de mi cargo satisfacer todos los costos y gastos que se impendan en la recepción del material, su acomodo, y resguardos necesarios, como igualmente las 4500 badanas, mas o menos que se necesitan, los cordeles de acarretto, la madera para la refacción de los cajones, que llegarian a ser muchos entre 1334 que se consideran deban venir. Los clavos, los oficiales de carpintería que debe conducir todo desde otras distancias, porno haber estas proporciones en Arica. Y asimismo los fletes, mozos que me ayuden, la manutención mia, y de ellos, cuya cuenta por menor ademas debe ser importuna, no es posible se prevea, sino se experimentan las ocurrencias bastante indispensables como remediadas unicamente a todo costo de dinero, y gentes en unos lugares remotos, y de escasezes tan notoria.

Item - que todos los utensilios de las se hagan cuales ellas sean de badanas, y cajones, quedarán en las mismas casas a favor de S.M. para que se vendan de segundas. Por tanto - a US pido y suplico se sirva hacerme por presentado en el grado que va referido, y conceptuase la susperioridad de US y fuere mas conforme al Real servicio". Francisco X. de Santelizes - Paz 26 de Mayo de 1789 .

Los ministros de la Real Hacienda contestaron afirmativamente los pedidos de Francisco Xavier de Santelizes. En carta de Crespo-Llano firmada el 8 de junio de 1789 en Paz, se menciona la cantidad de 5.502 pesos en total por concepto de flete,

"considerados todos sus destinos, distribuidos entre los 2000 quintales de azogue, pues la propuesta habla de $\$ 8$ por quintal, descontando los gastos. El costo de cada mula hasta destino es de $\$ 24$, considerando además $\$ 12$ por quintal en los azogues de Carangas, \$11 por La $\mathrm{Paz} \$ 9$ por Oruro, y\$6 por Chucuito, pero a Chucuito van 600 cajones, a Oruro, 433, hecho el conjunto 
que pagados todos los fletes de todos ellos en sus destinos, solo queda apara reparo y acomodo \$5502. Por lo tanto, y de ser tal, se le adjudique por ser conveniente".

Santelizes contestó el 20 de junio que, para mejor arreglo de las refacciones en el transporte del azogue propone hacerse cargo de las conducciones de dicho azogue bajo la propuesta equitativa que se le debe aguardar por vía refacción, hasta las casas de Chucuito el $2 \%$ de quintales, hasta La Paz el $1 \%$, a Oruro el 1 1/2\%, y Carangas el 1\%. El mismo Crepo-Llano oficia al Gobernador Intendente sobre el porcentaje aplicado a la distancia Arica-Oruro y La Paz, manifestando que es la misma distancia por lo que el porcentaje debe ser el mismo, es decir, de $1 \%$.

Así las negociaciones, se ordena se extienda la escritura correspondiente de contrato en favor de Santelizes, para que, extendida la fianza, reciba en el puerto de Arica 2.000 quintales de azogue y conducirlos, de acuerdo a instrucción del virrey:

600 cajones a Chucuito

433 cajones a Oruro

200 cajones a Carangas

100 cajones a Paz.

Dicho traslado se haría a razón de $\$ 8$ por quintal, y una refacción de $2 \%$ por merma en ios azogues destinados a Chucuito, y $1 \%$ por los restantes, y

"con la condición que se le ha de contribuir por delante $\$ 4$ por cada quintal, que es la mitad de los $\$ 8$ estipulados, y el resto se le ha de entregar por los Ministros de Las Cajas recibidoras, precedida la cuenta de cada entrega que haga con su respectiva refacción y abono de media libra de tasa en cada bollo o maito, y dejando en los respectivas casas a beneficio de S.M. los cajones y utensilios. El plazo de conducción y entrega es de cuatro meses contados desde su recepción en Arica, considerando que se harán varios viajes porque no hav recuals suficientes para transportarlos de una ida". (Escritura otorgada por el Teniente Coronel de ejército Dn. Protacio de Azmentia a Francisco Xavier de Santelizes, Paz Real Contaduría General 29 de junio de 1789).

Es interesante hacer notar que hasta aquí, la organización y procedimiento para tan importante traslado de azogue funcionaba de acuerdo a la burocracia de la Corona, adecuándose en algunos aspectos a las dificultades propias de la región. Pero, era de preverse que la ruta del tráfico de azogue por Buenos Aires no iba a cancelarse tan livianamente. En efecto, en la documentación anexa se encuentran alegatos en favor de mantener la conducción del azogue por la vía Buenos Aires-Salta. Uno de estos documentos señala el pedido reiterativo hecho por Francisco Díaz de Arenas, apoderado de Tomás Antonio Romero, asentista general de caudales y azogues del virreynato de La Plata, para que 
estos caudales sean trasladados por la vía del oriente, a fin de evitar entregar contratos de traslado a particulares, como era el caso de Santelizes. Los Ministros de Real hacienda fallaron, sin embargo, en favor del traslado por Arica, primero porque aunque se trata de particulares, ha sido ordenado por el Virrey, y además, porque representa economía, rapidez y seguridad.

De manera que el 3 de octubre de 1789 llega a las costas de Arica la fragata con el cargamento de 1.334 cajones de 11/2 quintal cada uno, procedente de Cádiz. El 27 de octubre es entregado al asentista Santelizes para su conducción al altiplano.

Los detalles del traslado, vía utilizada y problemas encontrados en el camino, desgraciadamente no los conocemos. En este aspecto, acudimos a documentación del Archivo de Arica, reflejadas en la obra de Vicente Dagnino (1909).

Hacia 1612, en pleno auge del traslado de azogue por Arica, Dagnino expresa que en la preparación de las expediciones participaba la mita de Ilabaya, Tarata y Putina, localidades ubicadas en el altiplano sur peruano, con unos "cuarenta indios. catorce de llabaya y veintiséis de Tarata y Putina, jurisdicción de esta ciudad, están como de costumbre viniendo a este puerto los seis meses de invierno para hacer las izangas para los arrieros que acarrean el azogue a S.M. a la villa del Potosí y Oruro; por ser el verano aquí muy enfermo para ellos, no asisten mas..." (Dagnino 1909:45).

Las izangas correspondían a los aparejos para los llamos. Se hacían originalmente de totora, abundante en los pantanos de la desembocadura del río Azapa. En épocas normales se disponía la confección de 6.000 izangas por temporada, lo que da una idea sobre la enorme cantidad de animales necesarios para el transporte del azogue y plata.

El acarreo de azogue se hizo en llamos, pero a partir de comienzos del siglo XVII se introdujeron las recuas de mulas. Sin embargo, parece que aún con la utilización de mulas, la organización del transporte siguió el mismo patrón de las organizaciones aymaras. Las recuas, por ejemplo, a pesar de lo numerosa, se dividía en grupos más pequeños de diez animales - las piarasy que podían ser manejadas por solo dos hombres.

Normalmente hacían jornadas diarias de 3 a 4 leguas, tardando entre 24 y 28 días el recorrido que incluía Oruro, Potosí y Carangas. La gran dificultad de la mula, sin embargo, es que no resiste las inclemencias del tiempo y la escasez de forrajes tan bien como las llamas, por lo que la mortandad de estos animales en cada acarreo era bastante elevada. Por ello, se necesitaba gran cantidad de animales de reserva. Sin embargo, en los siglos xVII y xvIII eran preferidos porque tenían mayor capacidad de transporte. Dagnino (1909:87) da el dato que anualmente se traían alrededor de ochenta a cien mil mulas desde la región central de Chile y desde Tucumán.

El azogue constituía un elemento de difícil transporte, debido a su elevado peso y la dificultad de embalarlo convenientemente. Por ello, se prefirió su 
transporte en contenedores de pieles curtidas - badanas-, con las que se hacían bolsas amarradas en sus extremos. El azogue que venía desde Europa, preferentemente de España, y conocido como azogue de Castilla, entraba a América por Panamá. Su forma de embalaje consistía en "atados de a cuatro badanas y cuatro ligaduras de hito de tralla, a razón de cuarenta libras por atado, que llamaban grande, el de Guancavélica llegaba en atados que llamaban chicos, de dos badanas y dos ligaduras, con peso de treinta libras más o menos" (Dagnino 1909:88).

Las badanas para los fletes se confeccionaban en el centro de Chile, y fue un negocio muy fructífero durante los siglos XVII a XVIII. Incluso muchos expedientes dan cuenta de una gran actividad clandestina del tráfico de estas badanas y cordobanes que entraban burlando la vigilancia de las Cajas Reales a Lima y Arica. Además, y debido a la demanda, sus precios eran altos, y la calidad no siempre respetada, lo que fomentaba escasez de badanas para el transporte.

El azogue era distribuido en las badanas. Cada par de badanas conformaba un maito, y aproximadamente cuatro maitos hacían un quintal. El azogue que venía de Guancavélica era embarcado en Chincha en naves de la Armada Real. Durante el siglo Xvıl hacían un viaje al año. Adicionalmente la Corona también fletaba mercantes particulares, especialmente en el siglo XVIII. El azogue era objeto de cuidados especiales en este transporte marítimo. Debía ser embalado en cajones para evitar el peso descontrolado en alta mar, estibando las badanas como mejor cupieren en dichos cajones.

Una vez en Arica el desembarque y reexpedición del azogue hacia el altiplano constituía toda una nueva empresa. Los arrieros hacían uso de los recursos locales, producto de siglos de tráfico organizado, pero a costa de tener que cancelar sumas cada vez más altas por la prestación de servicios de manutención y forrajes.

En este aspecto, es ilustrativo el documento que reseñamos en este trabajo. Los tambos a lo largo del valle de Lluta, según reseñan documentos, cobraban por servicios quince pesos por la hanega de maíz.

\section{EL TRÁFICO DE CARAVANAS EN LA ÉPOCA PREHISPÁNICA}

En la organización y dinámica de la sociedad andina el principio de complementariedad ha sido fundamental (Murra 1972). Bajo este principio, el hombre andino percibe su realidad y el entorno con un sentido macrovisionario, englobando áreas y nichos ecológicos muy diversos y variados, y que contribuyen a complementar sus posibilidades. Esta visión de la realidad tiene implicancias tanto para la vida social como económica, política y espiritual del pueblo andino. Lo intreresante es que, al parecer, éste es un ideal de muy larga gestación en el tiempo, y por ende, muy arraigado en las concepciones 
ideológicas del mismo, de manera que llegan a constituirse, aun hoy día, en fuertes pilares del pensamiento andino. Para lograr una complementariedad física que mantenga cierta unidad y destino el pueblo andino ha desarrollado al máximo las posibilidades de traslado a través de la organización de caravanas de llamas.

Son innumerables las evidencias arqueológicas que muestran como se han movido estas caravanas vinculando extensos territorios. Productos del altiplano, como chuñu, charki y papas eran bajados a los valles para ser intercambiados por aquellos del valle, por ejemplo maíz, sal y guano.

En 1975, y posteriormente en 1987, mientras nos encontrábamos realizando trabajos de terreno en los sectores de Belén, al interior de Arica, y en Camiña, sector localizado al sur de Codpa, tuvimos oportunidad de observar cómo funcionaban estas caravanas (véase también investigaciones de Flores (1985), Murra (1965 y 1975), Guerrero (1986), Orlove (1977), y Flannery et al. (1989).

Recorren estas caravanas enormes distancias. Tanto Belén como Camiña parecen representar punto finales de destino a llameros que vienen del altiplano y que bajan primero a las zonas orientales de contacto con la floresta tropical de la cuenca amazónica, para regresar al altiplano y bajar a las vertientes del Pacífico. Las localidades más frecuentemente mencionadas en los relatos de estos caravaneros fueron: Sabaya, Sajama, Turco, Corque, Andamarca, Coipasa, Pampa Aullagas, en el altiplano, y localidades orientales como Cotoca, Santa Cruz y Samaipata, Comarapa, Quillacollo y Cochabamba.

En 1985 la Corporación Nacional Forestal estimaba una población aproximada de 8.600 cabezas de llamas y alpacas para la zona de los altos de Arica (Rivera 1987:244). Gunderman, por su parte da una cifra estimativa de 10.000 cabezas de ganado camélido que, fue comercializado en 1982 en las principales ciudades del norte de Chile (Gunderman 1986:145). Evidentemente, la población camélida en el altiplano boliviano es aún mayor, y en el pasado, inmensamente mayoritaria y de enorme utilización.

En tiempos del imperio incaico, cientos de miles de llamas transitaron el camino real transportando mercancías del ejército. Estas caravanas estaban compuestas por llamas del Estado, pues normalmente, la propiedad individual de llamas estaba muy limitada. En los siglos siguientes, debe haberse producido toda una confusión para el hombre andino respecto a la organización ya estatuida de estas caravanas. Por un lado, la falta del poder central que fue reemplazado por el español, agudizado por las inclemencias de una mita que debía responder al trabajo de Potosí. Por otro, las cada vez más crecientes aspiraciones de los señores locales que, en un marco de mercantilismo en aumento, vieron favorecidas sus aspiraciones de romper con el esquema centralizado de la propiedad para desarrollar sus propias ganancias. La urgencia y la necesidad de transportar grandes cantidades de mercaderías, que 
incluían el azogue y la plata hacia y desde Potosí a Arica, favorecieron este esquema.

Hoy en día, la estructuración social interna entre los aimarás es un rasgo que ha sido destacado por Gunderman en sus recientes investigaciones (Gunderman 1986). Así, puede observarse la existencia de propiedad de camélidos a nivel individual como comunitario, aunque normalmente la función o actividad de llamero o caravanero es de características individuales.

Una recua de llamas de transporte está compuesta en promedio de unos 25 animales, de los cuales la mayoría son adultos machos. Esta misma conclusión es observada por Flannery siguiendo los análisis estadísticos de restos faunísticos arqueológicos (Flannery et al. 1989:104).

La carga promedio que un animal puede soportar es aproximadamente 25 kilos, dividiéndose en dos sacos de 12 a 13 kilos ( 1 arroba española), que se colocan a cada costado del llama.

En ocasiones en que debe transportarse mucha carga, se unen dos o más recuas de distintos dueños, conformando una caravana de varias decenas de llamas, pero organizada internamente siguiendo el patrón de una recua individual. Es decir, cada recua es liderada por un delantero que va guiando el resto de la recua. El delantero es muy apreciado por los pastores y normalmente se le viste con ornamentos llamativos de colores rojo, amarillo y azul. La época predilecta para la realización de estos viajes a larga distancia comienza inmediatamente después de la estación de lluvias de verano, es decir a partir de fines del mes de marzo. Normalmente viajan entre 15 a $20 \mathrm{~km}$ por día, y un viaje completo desde la ceja de selva a la costa Pacífico tomaba entre dos o tres meses.

Un aspecto interesante es la conservación del llama. En el ambiente seco del altiplano subsiste sin necesidad de cuidados específicos. Siendo el llama un camélido que puede subsistir largas jornadas sin alimentación, su alimentación a lo largo de los viajes está provista por lo que el paisaje puede ofrecerle en término de pastos y forrajes. Pero los ambientes costeros son malsanos. Una serie de pestes los ataca, sarnas y otros parásitos frecuentemente inundan sus cuerpos, así como debilitan sus pezuñas.

En general, la resistencia del llama a los climas húmedos y bajos de los valles costeros es muy precaria, por lo que los llameros aimaras cuando bajaban a Arica, mantenían lugares acondicionados para la guarda y pastoreo de estos animales en las partes medias de valle de Azapa, a la altura de San Miguel de Azapa al interior, con el objeto de evitar al máximo las infecciones que afectaban a estos animales. De cualquier forma, la mortandad de llamas en las tierras bajas era bastante alta, lo que indujo a utilizar la mula como medio de tranporte entre Arica y las haciendas interiores donde se encontraban las caravanas de llamas.

Mulas también fueron introducidas en gran número, sobre todo en el siglo XVII, por los españoles con el objeto de subir la capacidad de transporte de las 
mercaderías que iban a Potosí, pero, como veremos, el costo era alto pues las mulas no están adaptadas en las mismas condiciones que el llama a las alturas del altiplano. Normalmente, una caravana también lleva animales de reemplazo que no van cargados, con el objeto de alivianar la carga de aquellos que por el esfuerzo la requieren.

\section{PATRONES DE ESTABLECIMIENTOS DE PASTORES}

El estudio de Flannery et al. (1989) sobre pastores de llamas y caravanas es muy ilustrativo respecto de la asociación de éstos a tipo de establecimientos. Las formas más reconocidas son corrales, llamados también kanchas, que conforman complejos de estructuras habitacionales más expandidos y que incluyen casas de pastores, corrales más especializados para llamas, ovejas, cerdos u otros animales menores, espacios cercados o pircados para la elaboración de chuñu u otro producto agrícola, y collcas o silos. Complejos de esta naturaleza son muy comunes hoy en día en las comarcas de Socoroma, Belén, Putre, Chapiquiña, y en sectores del altiplano, notablemente en Isluga, Choquelimpie, Cariquima y Enquelga.

Todos estos establecimientos denotan, sin lugar a dudas, que forman parte de un conjunto mayor que constituye una infraestructura básica para los movimientos de caravanas desde el altiplano a los valles bajos. Pudimos estudiar mejor la dinámica de este fenómeno cuando en 1974 detectamos el funcionamiento de cinco comunidades altiplánicas en la cabecera del valle de Azapa, en el sector de Pampa Algodonal (Platt, 1975).

En cuanto a los registros arqueológicos, los más importantes señalan rutas de caravanas que se dirigen desde el altiplano al mar por los faldeos del valle de Azapa, también utilizando los valles de Chaca, Chiza y Camarones, y más al sur, Tiliviche, Quebrada Tarapacá, y el Loa. Conjuntos de diseños conformando petroglifos, pinturas, y especialmente, geoglifos, han quedado como trestigos del desplazamiento de estas caravanas (Núñez, 1976, Rivera y Marinov n.d., Briones y Chacama 1987).

\section{LAS EVIDENCIAS ARQUEOLÓGICAS AL INTERIOR DE ARICA}

Tanto en los inicios de este tráfico, cuando el transporte se hacía utilizando llamas, como más tardíamente cuando éste se hacía utilizando mulares, las recuas hacían efectivo uso de lo que les ofrecían los recursos locales. En este sentido podemos ver un desarrollo desde los primeros tiempos en que las facilidades otorgadas por los recursos locales eran consideradas dentro de un macrosistema, hasta el momento previo al impacto español, que funcionó con la redistribución incaica. En este sentido, los tambos y caminos de la amplia red vial cumplían funciones específicas que favorecían la organización de 
estos desplazamientos, y cada grupo local asumía responsabilidad para que el sistema efectivamente funcionara.

Los tambos que se encuentran ubicados al interior de los valles de Azapa y Lluta son muy importantes en este aspecto. Fueron piezas claves en el desplazamiento del tráfico incaico, y durante la ocupación española continuaron en uso, aunque con un sentido diferente. En este capítulo mencionaremos algunos de estos tambos para reforzar nuestro punto de vista del continuo tráfico del espacio sur andino (mapa 5).

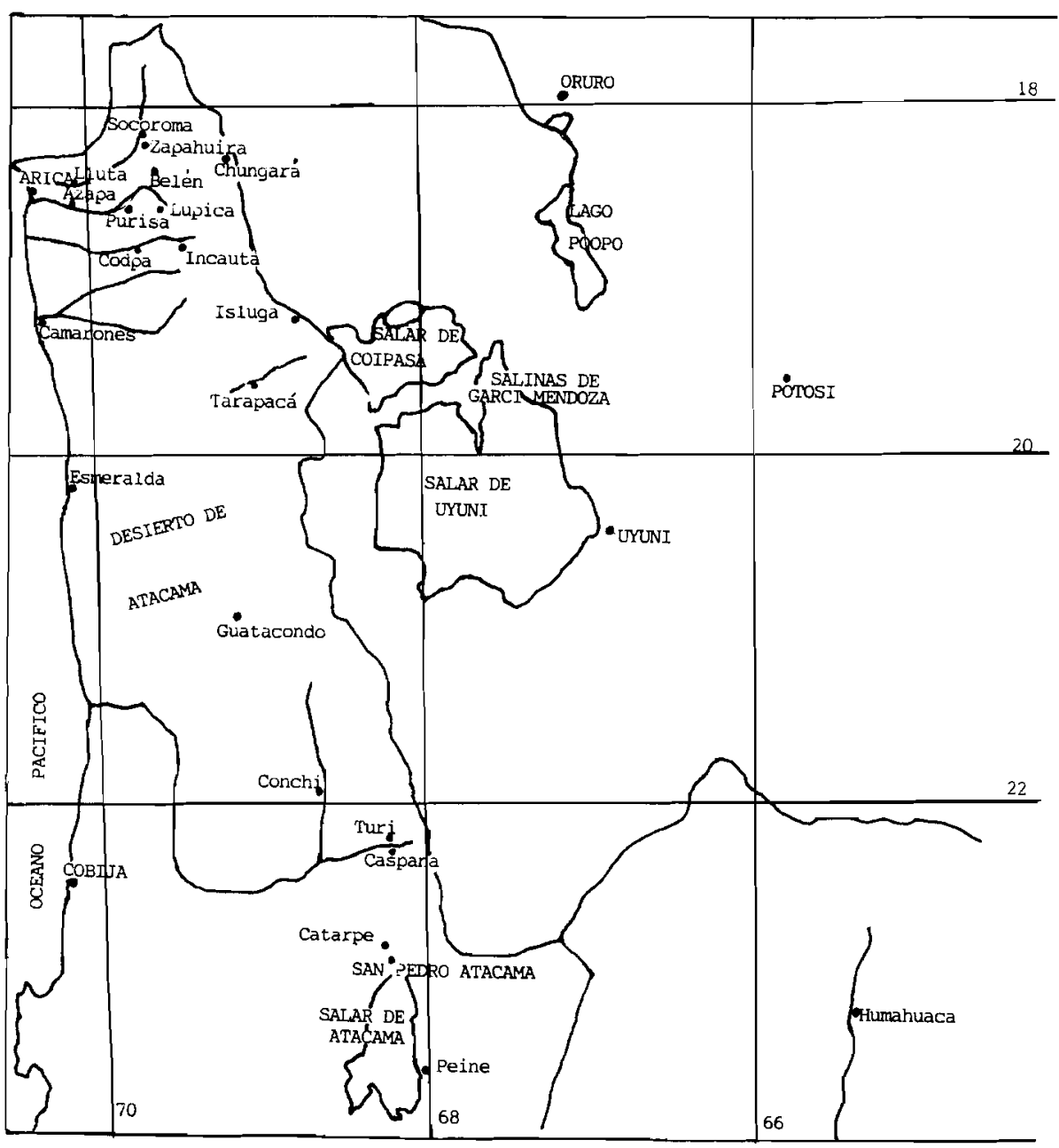

MAPA 5

Principales sitios arqueológicos en las rutas del Pacífico a Potosí en el norte de Chile. 
El uso de las vías de comunicación, y sobre todo el derecho a pasar por territorios foráneos incluía pactos y acuerdos estipulados previamente los que deben obedecer a una larga tradición. En este punto, la consolidación de normas de complementación y redistribución entre los diferentes grupos étnicos andinos es fundamental para comprender el grado de coexistencia y de prestaciones de servicios que hicieron posible los grandes logros de la civilización andina. Entre ellos, la facilidad y la frecuencia con que se realizaba el tráfico comercial desde los puertos del Pacífico hacia las tierras altas.

De acuerdo a los datos arqueológicos, la relación estrecha entre etnias altiplánicas y costeras ya existe en tiempos pre-Tiwanaku. La identificación de rasgos Pukara en el desarrollo Alto Ramírez hacia el 500 a. C. tanto en Azapa como Moquegua (Rivera 1991, Moseley et al. 1991) constituye un valioso punto de partida para futuras investigaciones.

Durante la hegemonía Tiwanaku estas relaciones se intensifican. No hay dudas que las diferentes etnias ubicadas fuera del núcleo Tiwanaku se encontraban en una relación incluyente bajo cierto tipo de estructura centralizada, y con una fuerte ideología que compartían (Rivera, 1985). En el período de desarrollos regionales que le sigue, las posibilidades de coexistencia étnicas continúan fortaleciéndose, probablemente favorecidos por experiencias anteriores y por la vigencia de una ideología común.

De este período existen ejemplos de grupos de distinta naturaleza que se contactan para realizar trabajos de gran envergadura, tendientes a fortalecer la producción económica regional. Esto les dará más fortaleza para contrarrestar posibles violaciones territoriales, a la vez que contribuye a reforzar el sistema de relaciones interétnicas que facilita la producción a través de funciones de reciprocidad tan comunes en el ámbito andino.

Obras hidráulicas de envergadura como la construcción de canales de larga extensión e intercomunicación de sistemas de riego, han sido muy bien estudiados en sitios como Socoroma (Santoro et al. 1988), Belén (Dauelsberg 1983) y Codpa (Muñoz et al., 1987).

También, como obras de envergadura, se desarrollaron obras viales, necesarias para la comunicación entre etnias diferentes. En los Altos de Arica, las vías no sólo bajan hacia la costa, sino también intercomunican en sentido vertical, puntos ubicados a cotas semejantes, predominantemente a lo largo de los 3.500 metros, y hacia el interior, constituyendo parte de un gran sistema intercomunicante. Etnias identificadas con los estilos arqueológicos San Miguel y Gentilar de la costa conviven con estilos definidos como Chiribaya primero, y luego Chilpe y Saxamar del Altiplano tanto en los valles de Azapa, Lluta, Codpa y Camarones, como en los de Sama y Moquegua. Más al sur, en Isluga y Cariquima se da una interrelación con Lípez, y en pleno desierto de altura, a partir de Guatacondo, y descendiendo al Salar de Atacama, la interacción de señoríos locales en los altos del Loa, Chiu Chiu y Conchi, Toconce, Caspana, Turi y San Pedro de Atacama, se intensifica, no sólo con 

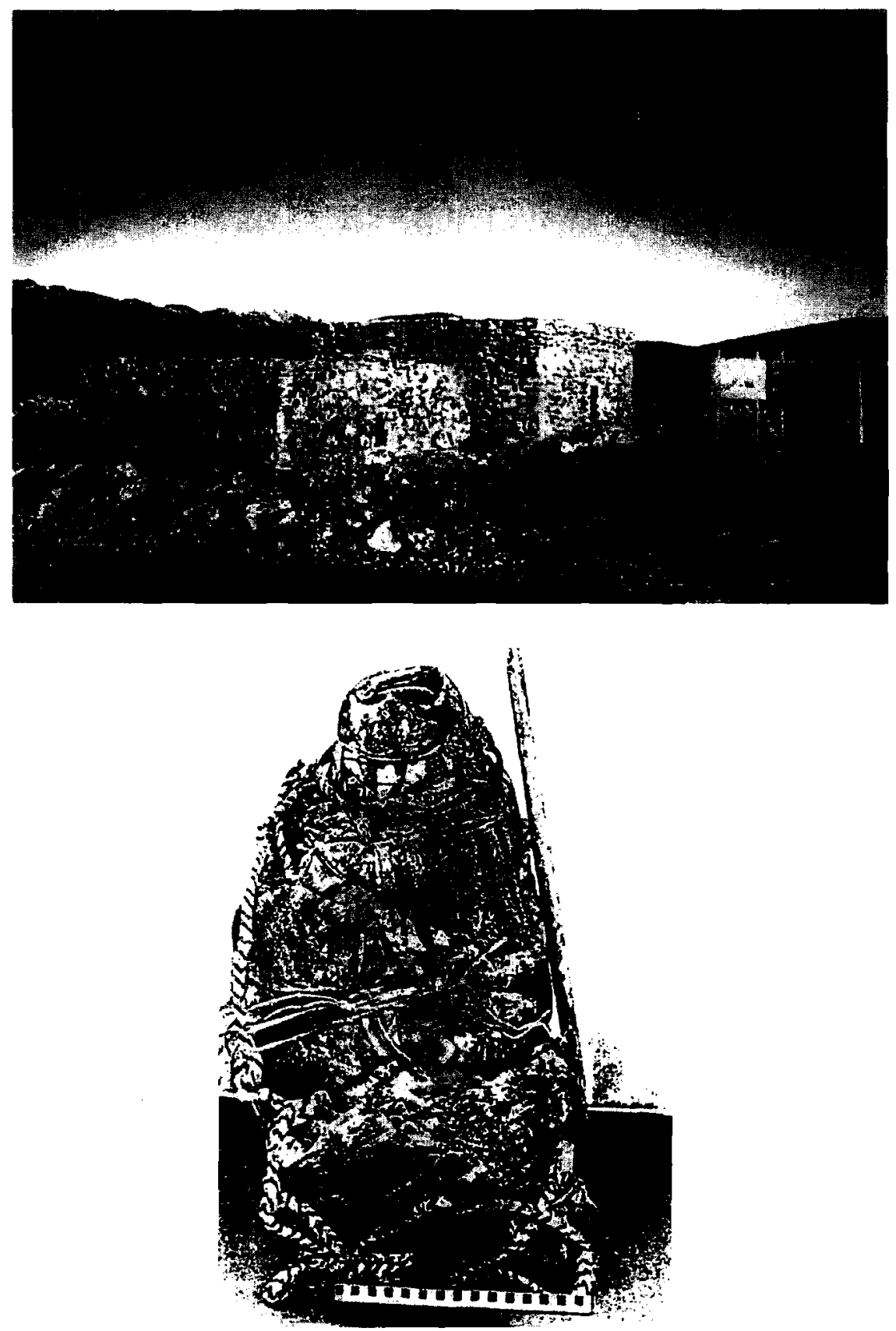

Arriha: Tambo Inciaco de Zapahuira (restaurado). Interior de Arica. Abajo: Personaje Sitio lncaico Camarones-8. 

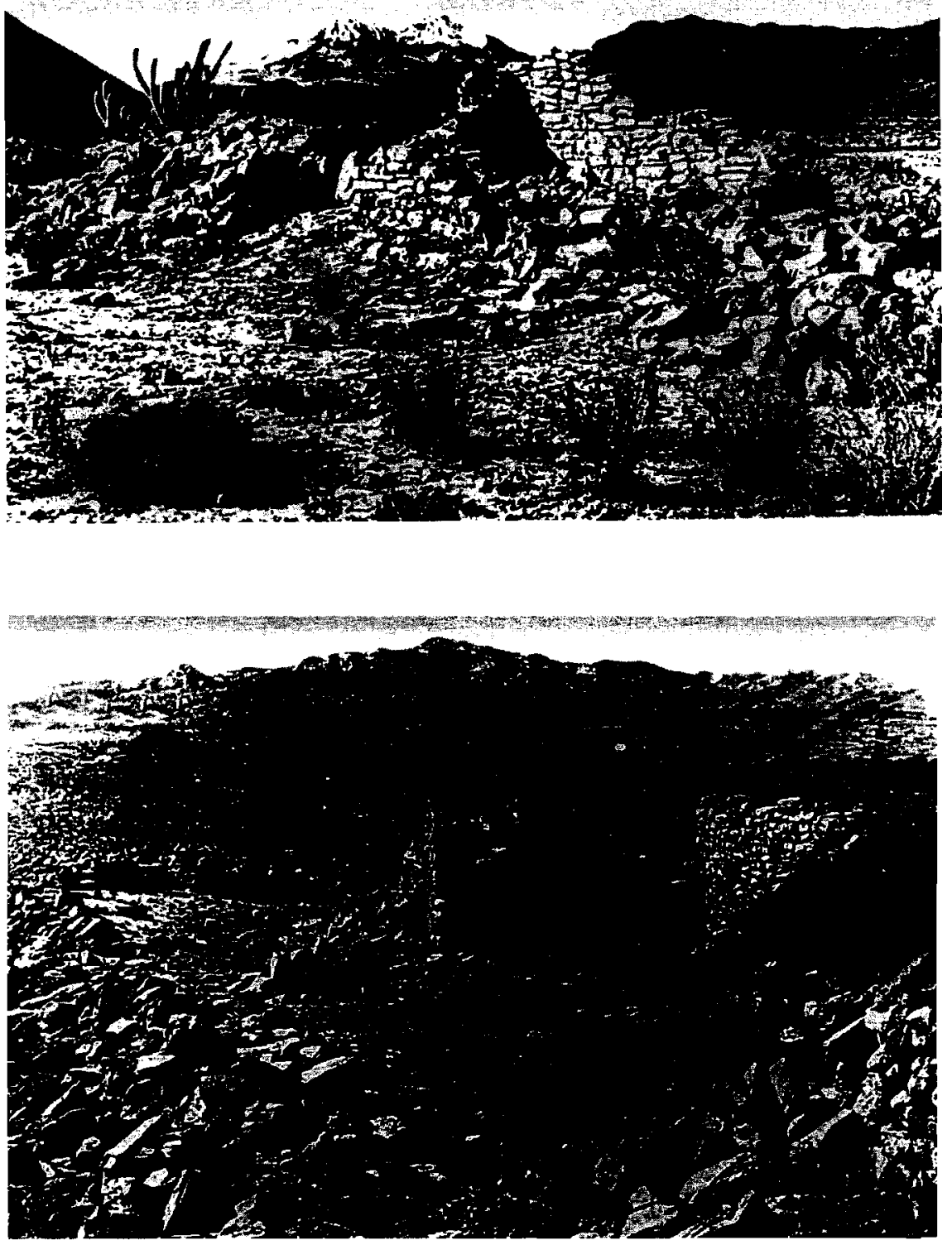

Arriba: Tambo Incaico de Zapahuira, Interior Arica, Ruta Potosí.

Abajo: Tambo Incaico de Peine, Alacama, Ruta Potosí-Oruro. 
grupos de Carangas y Lípez, sino también con Chichas y Omaguacas (Niemeyer et al., 1992-73), Hidalgo (1978), Fernández (1978), Rivera (n.d.).

Esta situación de enorme interacción y fomento de labores comunitarias de verdadero carácter empresarial son aprovechadas por la expansión incaica. $\mathrm{Su}$ organización jerárquica y centralizada, se superpone a las más débiles organizaciones políticas regionales. Las redes viales, por ejemplo, mantienen utilidad y aumenta su eficacia bajo una efectiva utilización basada en la administración centralizada. Por razones estratégicas, el aparato incaico rápidamente ocupa los puntos de acceso vial a los más importantes núcleos de producción regionales. Resulta instructivo observar el mapamundi incaico dibujado por Guamán Poma (1980), donde Arica, Guancavélica y Potosí aparecen relacionados, junto a los del Charcavana y Chuquiyapu (Poma 1980:913).

De allí que los enclaves incaicos se localicen en la precordillera de Arica, desde donde puede controlar el acceso del agua al valle. Entre éstos vale la pena mencionar los establecimientos incaicos en Socoroma, Belén, Zapahuira, Purisa, Chungará, Incauta. Más al sur, en pleno altiplano y en el desierto, el flujo a través del río Loa, y de aquellos caudales que alimentan los más importantes oasis. Entre los más connotados podemos citar: Camiña, Tarapacá, Isluga, Caspana, Turi, Catarpe y Peine. Todos estos establecimientos incaicos están dentro de una red vial que recorre el espacio tanto de norte a sur como de este a oeste, a lo largo de diferentes latitudes.

Cabe destacar que la red vial articulaba muy bien las distintas realidades, tanto étnicas como físico-geográficas del altiplano, los valles y la costa. A este respecto también podemos mencionar importantes enclaves incaicos en las tierras bajas costeras como Lluta, Azapa (sitios AZ-15, AZ-92, AZ-116), Camarones y cerro Esmeralda. Dauelsberg (n.d.), Llagostera (1976), Hyslop y Rivera (1984), Niemeyer y Rivera (1984), Hyslop (1984), Santoro (1983), P. Núñez (1981), Chacón (1985), Chacón y Orellana (1979), han documentado diferentes aspectos de la vialidad incaica en esta zona.

Finalmente, la ocupación hispánica también hizo uso de esta red vial, desde el mismo momento en que Almagro primero, y luego Valdivia incorporaron la región a la Corona. Tal como argumenta Orellana (1988:154-157), Valdivia entró por el norte de Chile siguiendo en gran parte el camino incaico. Éste lo hemos investigado con Dauelsberg (n.d.) desde Saguara a Zapahuira lugar en donde entronca con el tramo que viene de Tacna, siguiendo las cotas de 3.200 a 3.300 metros de altura, y con Hyslop y Niemeyer hasta el "despoblado" de Atacama (Niemeyer y Rivera, 1984, Hyslop y Rivera 1984).

Los conquistadores también hicieron uso de las rutas laterales y de aquellas que unen el altiplano con la costa. Así, en los relatos de la época Potosí y Tarija aparecen vinculados a las comarcas del desierto de Atacama. Según Bibar (1558), en Tarapacá recibió Valdivia las huestes de Francisco de Villagra que venía desde Tarija. Juan Jufré a su vez salió de Guatacondo a Potosí 


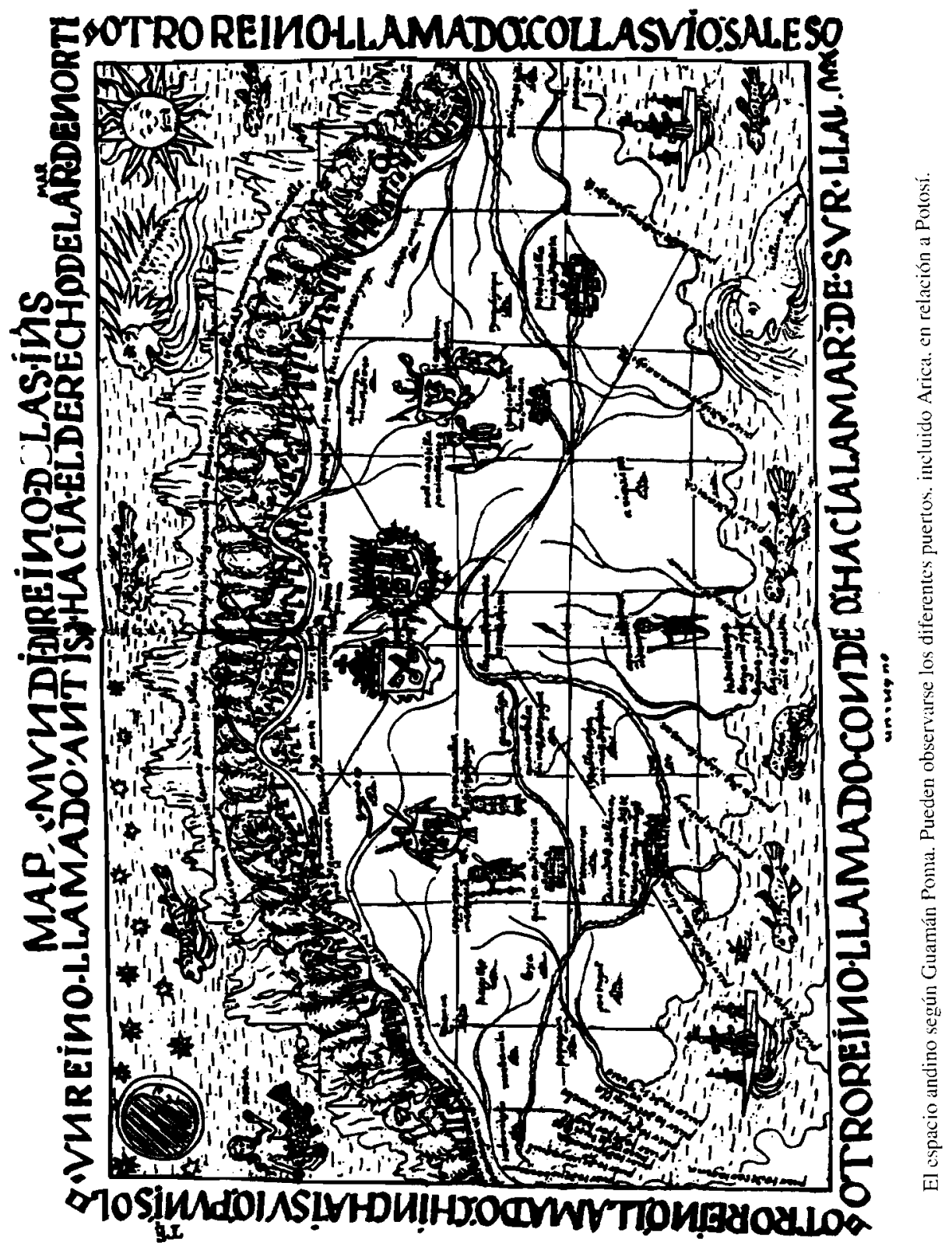


en busca de mayor ayuda, para reunirse posteriormente con Valdivia en Copiapó.

La mantención de estas rutas viales era esencial para los grupos étnicos que ocupaban esta región. El uso frecuente de ellas es importante y fundamenta las relaciones sociales y la producción económica dentro de los ideales andinos clásicos de reciprocidad y complementariedad. Existía por tanto toda una tradición y un conocimiento exhaustivo de ellos cuando los españoles incorporan el territorio y sus habitantes a la Corona. A partir del siglo XVI las fuentes andinas de producción comienzan a engrosar las arcas reales, y en esta situación las rutas viales juegan un papel decisivo. Sin embargo, es interesante dejar establecido que éstas no sufren alteraciones importantes en cuanto a trazado y otras obras de ingeniería. Aún más, continuarán siendo recorridas por los propios andinos sobre la base de la utilización de sus propios recursos. Platt (1987:229) da un ejemplo muy interesante al respecto. En pleno siglo XIX. en 1833, en la ruta de Potosí y Oruro a Cobija, Bartolomé de Navarrete solicita establecer cinco postas a lo largo del camino, en los puntos de Cobija, Calama, Canchas Blancas, Agua de Castilla y Poopó.

\section{AlgunAS CONCLUSIONES}

El presente trabajo constituye un intento por revalorizar las rutas de tránsito en el ámbito surandino. Antecedentes históricos y arqueológicos nos dan base para interpretar el significado de la dinámica de estas rutas en tiempo prehispánico o viceversa.

Hoy como en el pasado, hombres andinos surcan rutas inmemoriales vinculando espacios alternos, diferentes y complementarios, desde las costas tibias del Pacífico, a las tierras heladas de la puna, uniendo los paisajes del valle, de la precordillera y de la meseta altoandina, trayendo y llevando recursos que a través del tiempo no han cambiado esencialmente su significado para la comunidad, y en medios que, aunque introduciendo tecnología más adecuada a los tiempos, es imposible que puedan funcionar sin una organización que los respalde, y un conocimiento de los distintos nichos y especificidades ecológicas que contribuyan a su éxito.

Desde los tiempos incaicos en que un eficiente sistema de distribución utilizando caravanas funcionó en la mantención del imperio, a los tiempos de la explotación europea en que las rutas mantuvieron la dinámica de la sociedad andina, a los tiempos actuales, donde, a pesar de las circunstancias, miles de camiones surcan las rutas uniendo, a través del espacio, la diversidad y reforzando la hegemonía.

El ejemplo de Francisco Javier de Santelizes demuestra que, a pesar de existir argumentos favorables que decían relación con cierta economía de tiempo, con aspectos administrativos-empresariales y políticos que favorecían un mejor con- 
trol, el tráfico del azogue, que debía hacerse a fines del siglo XVIII por Salta y Jujuy hacia Potosí, fuera interrumpido por la peligrosidad de pueblos autóctonos (lules) en las regiones del Tucumán y Tarija, transformando una empresa viable, en prácticamente imposible (véase mapa 3 y especialmente 4).

Aun cuando la factibilidad de utilizar rutas por el Pacífico ya estaban dejadas por el tiempo, en la adversidad surge la posibilidad de realizar esta empresa para remediar la situación. En este sentido, el documento que se entrega es instructivo pues señala que se actúa en un terreno conocido y ante la emergencia, contra el tiempo, teniendo la certeza que puede ser recuperado.

Las vías de comunicación al igual que muchos aspectos tecnológicos propiamente andinos, continúan vigentes durante los siglos de imposición europea. La administración real española no interviene mayormente sino al final del proceso para recoger el producto y los beneficios. Siendo la organización de un traslado de azogue un fenómeno tan complejo, que demanda conocimiento exhaustivo de cada paso a lo largo del trayecto, los españoles no fueron capaces de dirigir estas empresas, $y$, desde muy temprano, entregan completamente esta responsabilidad a los andinos.

Es probable que teniendo más elementos de juicio sobre el uso y desarrollo de las vías de comunicación en la colonia podamos tener también mejores argumentos para establecer de qué forma la sociedad andina lograr mantener su balance, reemplazar los bienes trasladados y, en última instancia, comercializarlos o trocarlos, tal como ocurre en la actualidad. Platt (1987) nos da una buena perspectiva de lo que ocurre por el siglo XIX. Sin embargo, no sabemos hasta qué punto el intercambio no monetario o las transaciones bursátiles son dominantes. Al parecer, tanto entonces como ahora, ellas permanecen en un perfecto equilibrio, aunque con Potosí, decididamente el mercantilismo se impone sobre formas más tradicionales. Aunque, al parecer, como una forma necesaria para estimular las formas tradicionales, puesto que éstas no se han perdido.

Según hipótesis de Tandeter y Wachtel (1983), hacia fines del siglo XVIII, hubo un contacto más directo entre la producción y los precios con aquellas cantidades que se manejaban por trueque, lo que interpretamos como un resultado de la influencia producida por Potosi y que en definitiva corresponde a una adecuación del equilibrio que existe en la sociedad andina, incluida las transacciones mercantiles en la colonia. En esta adecuación, las rutas viales han jugado un papel importante pues le permiten al hombre andino continuar siendo el actor indispensable en el desarrollo económico, aun cuando el destino de la producción escapa a Europa, y se introduzcan aspectos económicos abstractos.

Browman (1981), definiendo su "modelo altiplano" da gran importancia al fenómeno de integración económica producido en época Tiwanaku, y basado en las redes extensas de interacción de caravanas. Básicamente, y de acuerdo a Browman, el rol de caravanero trasunta labores artesanales o de 
especialización, mercados y empresas similares, interconectando todas estas actividades y niveles sociales integrando el altiplano con otras zonas, dándole poder de iniciativa y control a centros basados en el altiplano, especialmente en las márgenes del lago Titicaca.

El sistema de caravanas, ligado al pastoreo andino prehispánico, fue directamente aplicado a los traslados de azogue durante la colonia. Estos últimos, que constituyeron empresas organizadas a efecto de trasladar el azogue, fue posible porque existía una tradición sobre caravanas de camélidos como forma de vida en donde los grupos humanos son flexibles y móviles, y donde el concepto de territorialidad y límites prácticamente desaparece frente a la necesidad de acceder a fuentes de producción, con elementos claves como el agua y los pastos, recursos que deben ser compartidos.

El objetivo es hacerlos funcionales e incorporarlos a la realidad propia del sistema. El seguir utilizando las vías de comunicación constituye para el andino una fuente de recursos que le posibilita seguir funcionando en su propia estructura, por una parte, y relacionarse con el sistema mercantilista europeo, por otra. Así, lentamente desarrolla su propia organización económica que fortalece lo social, compatibilizando su propia historia con los tiempos diferentes que vienen.

Gunderman (1986-87:242) nos relata cómo los pastores andinos que viven al interior de Iquique dinamizan el comercio de la costa con el altiplano, en otra forma de reinterpretación del propio sistema andino a las influencias de las zonas francas comerciales de Arica e Iquique, en pleno siglo xx.

La condición social del arriero azoguero es muy interesante.

Constituye en el tiempo una primera forma de enriquecimiento que rompe el esquema del equilibrio interno andino, especialmente aymara, constituyéndose en un pequeño señor con atributos mercantiles. Pero mantiene prestigio y posición dentro del grupo aymara por lo que podemos ver en él una forma necesaria de adaptación social y económica a la nueva situación mercantilista europea. Se constituye en un ente de enlace entre los dos tipos de economías, y un agente estabilizador hacia el interior de la sociedad andina.

Es éste probablemente el inicio de la situación que hoy viven quienes, montados en modernos caballos de hierro con motor, trasladan enormes cantidades de recursos desde la costa templada a la puna fría, avanzando en bloques de cuatro a cinco vehículos, agrupándose de noche, para juntos, con verdadero sentido empresarial, continuar la larga tradición señalada con la experiencia de Potosí.

Agradecimientos

A José Antonio Pérez, Ana María Llamazares, Alberto Rex González, y CONICET que hicieron posible mi estada como investigador en Buenos Aires 
durante 1990-91; a mi familia, Ximena, Andrea, Daniels y Mario José, y a mi padre Ángel, quienes apoyaron mi programa a pesar de las circunstancias adversas generadas por el autoritarismo insensible y la poca percepción de las autoridades de la Universidad de Tarapacá en 1988, y que determinaron mi salida involuntaria de la misma y nuestro arraigo fuera del país. A la Directora del Archivo General de Indias Sra. Rosario Parra y Sra. María Belén García, especialista de América Andina del mismo Archivo, y a la Embajada de España en Santiago, Gobierno de España y Ministerio de Asuntos Exteriores, Dirección de Relaciones Culturales, especialmente al Sr. Fernando Peral Calvo, Director Jefe de Intercambios, Mercedes y Christian Abello, quienes hicieron posible mi estada en Sevilla en 1988.

\section{BIBLIOGRAFIA}

Bibar, Gerónimo de (1558) 1966. Crónica y Relación Copiosa y Verdadera de los Reynos de Chile. Fondo Histórico y Bibliográfico José Toribio Medina, Santiago.

Bittmann, Bente, 1983. Cobija, Panorama etnohistórico en relación a los informes del Dr. José Agustín de Arze, 1786-1787. Chungará 10:147-153.

Briones, Luis, Juan Chacama, 1987. Arte rupestre de Ariquilda; Análisis descriptivo de un sitio de geoglifos y su vinculación con la prehistoria regional. Chungará 18:15-66.

Browman, David, 1981. New Light on Andean Tiwanaku. American Scientist 69:408-419.

Cañete y Domínguez, Vicente (1791) 1952. Descripción Geográfica, Histórica, Física y Politica de la Villa Imperial y Cerro Rico del Potosí y de los Partidos de Porco, Chavanta. Chichas o Tarija, Lipez y Atacama. Ediciones Potosí, Colección Cultura Boliviana.

Chacón, Sergio, 1955. Tambo Chungará. Imagen l (1):42-45.

Chacón, Sergio y Mario Orellana, 1979. Tambo Chungará. VII Congreso Arqueología chilena, Actas, pp. 247-255.

Dagnino, Vicente, 1909. El Corregimiento de Arica, Imprenta la Época, Arica.

Dauelsberg, Percy, 1983. Investigaciones arqueológicas en la sierra de Arica, Sector Belén. Chungará 11:63-83.

n.d. El Camino del Inca en la Sierra de Arica, manuscrito en el Instituto de Antropología Universidad Tarapacá.

Dillehay, Tom, Lautaro Núñez, 1988. Camelids, Caravans, and Complex Societies in the South Central Andes. En Saunders y Montmollin (eds.). Recent Studies in Precolumbian Archaeology, BAR International Series 421:603-634.

Fernández, Jorge, 1978. Los Chichas, Los Lípez y un posible enclave de la cultura San Pedro de Atacama en la zona limítrofe Argentino-Boliviana, Estudios Atacameños 6:19-35.

Flannery, Kent, Joyce, Robert Reynolds, 1989. The Flocks of the Wanani, Academic Press.

Flores, Jorge, 1985. Interaction and Complementary in Three Zones of Cuzco. En Masuda, Shimada y Morris (eds.) Andean Ecology and Civilization, Tokyo University Press.

Guerrero, Raúl, 1986. Los camélidos sudamericanos y su significado para el hombre de la puna. Diálogo Andino 5.

Gundermann, Hans, 1986. Comunidades ganaderas, mercado y diferenciación interna en el altiplano. Chungará 16-17:233-250.

Hidalgo, Jorge, 19 78. Revista de los altos de Arica en 1750. Universidad del Norte, Arica. 1983, Dos documentos inéditos y un mapa de Cobija: informes del comisionado Dr. José Agustín de Arze, 1786-1787. Chungará 10:139-145. 
Hyslop, John, 1984. The Inka Road System, Academic Press.

Hislop, John y Mario A. Rivers, 1984. The Inka Road in the Atacama Desert, Archaeology 37(6): 33-39.

Llagostera, Agustín, 1976. Hipótesis sobre la expansión incaica en la vertiente occidental de los Andes Meridionales. Anales Universidad del Norte 10:203-218.

Larrain, Horacio, 1974. Documentos relativos al Norte Grande. Norte Grande I(2):233-251.

Moseley, Michael, Robert Feldman, Paul Goldstein, Luis Watanabe, 1991. Colonies and Conquest: Tiahuanaco and Huari in Moquegua. [sbell and McEwan eds. Huari Administrative Siructure, pp. 121-140, Dumbarton Oaks Research Library and Collections, Washington D.C.

Muñoz, Iván, Juan Chacama, Gustavo Espinoza. 1987. El poblamiento prehispánico tardío en el valle de Codpa. Chungará 19:7-6.1

Murra, John V., 1965. Herds and Herders in the Inca State. En A. Leeds y A.P. Vayda (eds.) Man, Culture and Animals, pp. 185-215. American Association for the Advancement of Science.

, 1972. El control vertical de un máximo de pisos ecológicos en la economía de las sociedades andinas Visita a la provincia León de Huánuco (1562) por Iñigo Ortiz de Zúniga, vol. 2, pp. 427-476, Universidad Hermilio Valdizán, Huánuco.

Niemeyer, Hans, Virgilio Schiappacasse e Iván Solimano, 1972-73. Padrones de poblamiento en la quebrada de Camarones (provincia de Tarapacá), Actas VI Congreso Arqueología Chilena, Boletin de Prehistoria, pp. 115-137, Universidad de Chile, Santiago.

Niemeyer, Hans y Mario A. Rivera, 1984. El Camino del Inca en el despoblado de Atacama. Boletín de Prehistoria Chilena 9:91-193.

Núñez, Lautaro, 1976. Geoglifos y tráfico de caravanas en el desierto chileno. Anales Universidad del Norte 10:215-241.

Núñez, Patricio, 1981. El Camino del Inca. Creces 10(2):49-57.

Orellana, Mario, 1988. La Crónica de Gerónimo de Bibar y la Conquista de Chile. Editorial Universitaria, Santiago.

Orlove, Benjamin, 1977. Alpacas, Sheep and Men: The Wool Export Economy and Regional Societies in Southern Peru. Academic Press.

Poma de Ayala, Guamán, 1980. Nueva Crónica y Buen Gobierno. Editorial Siglo Veintiuno.

Platt, Tristán, 1975. Experiencia y experimentación: Los asentamientos andinos en las cabecerás del valle de Azapa. Chungará 5:33-60.

1987. Calendarios tributarios e intervención mercantil. Racionalidades estacionales entre los Indios de Lípez (Bolivia) en el siglo xIX. Chungará 19:215-241.

Rivera, Mario A., 1985. Alto Ramírez y Tiwanaku. Un caso de interpretación simbólica a través de los datos arqueológicos en el área de los valles occidentales, sur del Perú y norte de Chile. M.A. Rivera, ed. La problemática Tiwanaku Huari en el contexto plan Andino del desarrollo cultural, Simposio del 45 Congreso de americanistas, Diálogo Andino 4:39-58.

1987. Land Use Patterns in the Azapa Valley, North of Chile. Browman, D., ed. Arid Land Use Strategies and Risk Management in the Andes. Westview Special Studies. pp. 225-250, Denver.

1991. The Prehistory of Northern Chile, A Synthesis. Journal of World Prehistory $5(1): 1-47$.

, n.d. Relaciones Interétnicas en zonas de frontera durante el desarrollo Tiwanaku: una visión del N.O. Argentina desde San Pedro de Atacama, Manuscrito para CONICET, Buenos Aires, en poder del autor.

Rivera, Mario A. y Branko Marinov, n.d. Excavaciones en laguna Este-I. Manuscrito Universidad de Chile. Antofagasta.

Santoro, Calogero, 1983. El Camino del Inca en la Sierra de Arica, Chungará 10:39-46. 
Santoro, Calogero, Jorge Hidalgo y Alfonso Osorio, 1988. El Estado Inka y los grupos étnicos en el sistema de riego de Socoroma. Chungará 19:71-92.

Tandeter, Enrique y Nathan Wachtel, 1983. Conjontures Inverses: Le Mouvements des Prix à Potosi Pendant le XVIII siêcle, Annales ESC 3 pp. 549-613. 